Brit. J. soc. Med. (1949), 3, 101-109.

\title{
VISUAL TESTS OF FATIGUE IN OPERATIONAL FLYING
}

\author{
BY \\ D. D. REID \\ From the London School of Hygiene and Tropical Medicine, University of London, and lately of the \\ Directorate-General of Medical Services, Royal Air Force
}

The recurring problems in the medical supervision of men engaged in operational flying in the Royal Air Force were the optimum length of the tour of duty to be expected of them and the detection of the point in that tour of duty when an individual was showing signs of impending breakdown. The length of the tour of duty had to be laid down as a general rule for each type of operational dutywhether fighter, bomber, coastal command, etc.and set at a level which obtained for the Service an adequate operational return for the training investment made and yet was compatible with the maintenance of health and morale. Within the broad guide of this general tour limit, some latitude had to be allowed for individual variation. Breakdown in any individual may be the result of some particularly harassing experience or the cumulative effect of stress on a man of less robust nervous constitution. The release of a flying man from operational duty should anticipate complete breakdown but, if group morale is to be maintained, relief should not follow the appearance of slight deviations from normal function. Few men survived an operational tour without showing some evidence of the effect of stress, whether symptomatic or objective, and it would have been unfair to relieve only those who brought these complaints to the squadron medical officer. Occasions arose, too, where the squadron doctor was asked to state whether a man who was suspected, if not of malingering, at least of magnifying the physical and mental disturbances inevitable in air warfare did in fact show objective signs of undue physical reaction to the operational environment. The distinction between the normal (in the sense of usual) reaction to strain and abnormal reactions which might portend neurotic illness was necessarily a fine one, and the appreciation of lesser degrees of abnormality presupposed a precise knowledge of the limits of normal variability round the average. Upon such knowledge rested many of the hopes that medical supervision could make a useful contribution to the prevention by anticipation of psychological disorder in flying crews.

A considerable body of experience of the characteristic patterns of symptoms, behaviour, and operational performance was obtained in the various Commands of the R.A.F. (Symonds and Williams, 1947). During most of the war, however, little information was available about the objective physical measures of stress either as a group or individual phenomenon. Given such physical measures, it should be possible to make a quantitative assessment of the effects of stress in a homogeneous group of flying men, e.g. night-fighter pilots, and to determine whether, for example, there was a critical point in the prevailing length of tour of duty expected of them beyond which a consistent deterioration set in. Again, if the individual variability round the general trend of the physical index used could be measured, the significance of an individual's aberrant reaction could be readily assessed in terms of this index.

Some work done on this subject has already been reported (Reid, 1947). Weighing a large group of men engaged in night bomber operations at one point in time demonstrated that, compared with those who had not started their operational tour, men who had done up to 12 bomber sorties showed a drop in weight of about $2 \mathrm{lb}$. After the twelfth sortie, stabilization took place and weight was maintained about that level in those who survived. That this drop in weight probably signified that fluctuation in body weight was objective physical evidence of the effects of stress was suggested by contemporary evidence of an increase in the incidence of psychological disorder and minor sickness during the first part of the tour and a fairly stable rate thereafter. This meant that in so far as these indicators were valid, there was no point within the general tour limit of 30 bomber sorties beyond which a consistent decline in health and morale appeared. 
This approach involved the measurement, at one point in time, of different men at different stages in their operational tour. It had the practical advantage that it produced a useful answer relatively easily and quickly, since there was no need to follow a series of men over a tour lasting perhaps six to nine months. But there was no doubt that the alternative method of performing repeated measurements on the same individuals over a period of time was intrinsically more attractive. Despite the very considerable administrative difficulties involved, it had the advantages that it eliminated, by measuring the same man at different stages of his tour, the variation between individuals which might blur a trend in the index over a number of sorties. Again, although the first method was necessarily limited by the numbers involved to a crude measure such as bodyweight, the possibility of observing a small group of individuals permitted the use of more elaborate and thus perhaps more sensitive objective measures of physical deterioration.

It was decided, therefore, to look for rather more finely balanced physiological functions which might be expected to react sensitively to environmental stresses on the individual, yet which would be susceptible to reliable measurement. The importance of vision in flying and the special experience of the medical branch of the R.A.F. in applying tests of visual function made the choice of such tests appropriate. The Consultants in Neuropsychiatry and Ophthalmology, Air Vice Marshals Sir Charles Symonds and P. C. Livingston, therefore agreed to initiate a field trial of tests of visual function as a physical measure of the effects of operational stress in night bomber crews.

\section{OUtLine OF Method}

The special tests of visual function selected for study were, with one exception, those used routinely in the selection of men for flying duties in the R.A.F. The technique of measurement in each case is described in full in the Air Ministry publication "Medical Examination for Fitness for - Flying" (1941). Tests of visual acuity were included in the survey, but the main emphasis lay on tests of visual judgment or of ocular balance. The function of accommodation in particular was thought to be most liable to upset by general strain. All the tests available for the detection of ocular muscle imbalance were used, and a test of physiological diplopia, then being developed by Livingston, was added. The final selection thus included

Bishop Harman Diaphragm Test.-This is designed to estimate " the desire for binocular vision." This is a dissociation test where an adjustment is made $\frac{\pi}{2}$ for inter-pupillary distance and the degree of exo-? phoria or esophoria indicated on a scale calibrated $\underset{\stackrel{\rho}{?}}{\vec{*}}$ from 0 to over 8.

Maddox Wing Test.-This is likewise a dissocia-등 tion test of ocular poise where the esophoria or exophoria is recorded in terms of dioptres.

Binocular Gauge Test.-This is a test of accommo- $\frac{}{0}$ dation where the distance from the eye at which ${ }^{\text {s }}$ convergence on accommodation is seen to break $\overrightarrow{0}$ down is measured in centimetres for each eye $\overrightarrow{+}$ separately.

Experimental Test of Physiological Diplopia. $\frac{\stackrel{\circ}{\circ}}{\circ}$ This was designed to estimate the degree to which? this function was affected by continued operationa $\dot{k} \omega$ strain. In this instance, the results were expressed in degrees.

All these tests were applied in a rigidly standard-o ized fashion throughout the experiment by the same orthoptist (Section Officer J. Norman,,$\vec{C}$ W.A.A.F.). Before the field trials began, repeate assessments were made on the same individuals at intervals of some days to gauge the reliability of the measures used. These preliminary trials proved satisfactory and the field studies were started ato a base from which were operating a squadron of Mosquito aircraft (carrying a pilot and navigatoro only) and a squadron of Lancaster aircraft carrying the usual crew of seven. Both squadrons belonged $Q$ to the Pathfinder Force of Bomber Command and $\overrightarrow{5}$ to that extent were selected from the main body of $\bar{B}$ the heavy night bomber force. The operationa role of the two squadrons differed slightly, but in general they both shared the environmental condi tions prevailing in Bomber Command of the R.A.F $\stackrel{\bigcirc}{-}$ during the intensive efforts of 1944.

At the outset of the field study, all availableoperational crews were examined at rest duringo the day. The results of this examination then formed the base line from which subsequent deviations could be measured. At the same times the individual's operational experience, counted in the number of sorties performed to date, was recordedt together with his crew duty and his level of day visual acuity.

At intervals during the remainder of their tourw these men were examined on their return from are operational sortie. Their experience (in sorties) ato each examination, and the details of the weather height, range, and opposition met with during that particular sortie, were noted. As fresh replacements arrived for the squadrons, they too were includeof in the survey.

After some months there thus became available a series of measurements on the same individual a 
different stages in his operational tour. The average value for each of the measures proposed could then be worked out for each stage, 0, 1-5, 6-10 sorties, etc., and the general trend compared with previous results in this field. A review of the variation between the duration of individual sorties showed that it was too small to make possible any useful comparison between visual changes after sorties differing in duration or type. Attention was therefore mainly given to the behaviour, within a group, of visual function as a response to stress and to the deviation of an individual at different stages throughout the tour both from his own and from the group norm.

\section{SuMMARY OF RESULTS}

From the data available, one reading for each type of measurement for each individual was taken at the nearest point to the later limit of the experience grouping, 1-5, 6-10, 11-15, 16-20, 21-30 sorties. At this point, it was assumed, the effect of cumulative stress between, say, the sixth and tenth sortie would have been at a maximum. If no significant trends were visible using this material, then it was unlikely that any other method of selection, e.g. taking the median observation within the experience group, would have produced significant findings.
Accommodation.-Accommodation fatigue has long been considered a prominent sign of general fatigue. Taking this visual function first, then, we can set out the results of the Binocular Gauge Test of accommodation as in Table I. The differences between the results given by right and left eyes are negligible (in fact the correlation between them is $r=0.9044, n=100, P<0.01)$ and the two readings have been combined to give the mean accommodation averaged in each section of the operational tour in Table I. .

The trend seen in the "total" row is fairly consistently evident in each of the various types of crew duty in both squadrons. In the Lancaster squadron, the level at which objective failure in accommodation occurs rises to a peak about the tenth sortie and remains fairly stable at that level during the remainder of the tour. This trend, which is suggestive of an initial period of adaptation to stress followed by a period of stabilization, is very similar to the trend in weight loss and in the incidence of psychological disorder already noted. It seems reasonable to suppose that all three measures indicate the group reaction in a heavy night bomber formation to a tour of duties of 30 operational sorties.

On the other hand, although the basic trend of

TABLE I

Mean Accommodation Scores (R. and L.) at Different Stages of Tour

\begin{tabular}{|c|c|c|c|c|c|c|c|c|c|c|c|c|}
\hline \multirow{3}{*}{ SQUADRON } & \multirow{2}{*}{\multicolumn{2}{|c|}{ Resting }} & & \multicolumn{4}{|c|}{ Stage in Tour } & \multirow{2}{*}{\multicolumn{2}{|c|}{$21-30$}} \\
\hline & & & \multicolumn{2}{|c|}{$1-5$} & \multicolumn{2}{|c|}{$6-10$} & \multicolumn{2}{|c|}{ 11-15 } & \multicolumn{2}{|c|}{$16-20$} & & \\
\hline & No. & Score & No. & Score & No. & Score & No. & Score & No. & Score & No. & Score \\
\hline LANCASTER & & & & & & & & & & & & \\
\hline $\begin{array}{ll}\text { Pilot } & \ldots \\
\text { Navigator .. } & \ldots \\
\text { Air bomber } & \ldots \\
\text { Wireless operator } & . \\
\text { Flight engineer } & \ldots \\
\text { Air gunner } & \ldots \\
\end{array}$ & $\begin{array}{r}10 \\
12 \\
11 \\
8 \\
5 \\
19\end{array}$ & $\begin{array}{l}8 \cdot 85 \\
9 \cdot 33 \\
9 \cdot 05 \\
9 \cdot 28 \\
9 \cdot 20 \\
9 \cdot 21\end{array}$ & $\begin{array}{r}10 \\
12 \\
11 \\
8 \\
5 \\
19\end{array}$ & $\begin{array}{r}9 \cdot 95 \\
11 \cdot 70 \\
10 \cdot 95 \\
10 \cdot 67 \\
11 \cdot 52 \\
10 \cdot 38\end{array}$ & $\begin{array}{r}10 \\
12 \\
11 \\
7 \\
5 \\
18\end{array}$ & $\begin{array}{l}11 \cdot 88 \\
12 \cdot 74 \\
10 \cdot 40 \\
11 \cdot 26 \\
11 \cdot 50 \\
10 \cdot 22\end{array}$ & $\begin{array}{r}7 \\
7 \\
9 \\
4 \\
5 \\
12\end{array}$ & $\begin{array}{l}10 \cdot 76 \\
12 \cdot 46 \\
10 \cdot 67 \\
10 \cdot 75 \\
12 \cdot 35 \\
11 \cdot 16\end{array}$ & $\begin{array}{r}5 \\
5 \\
6 \\
5 \\
5 \\
10\end{array}$ & $\begin{array}{l}10 \cdot 80 \\
11 \cdot 75 \\
10 \cdot 41 \\
10 \cdot 64 \\
11 \cdot 92 \\
11 \cdot 07\end{array}$ & $\begin{array}{l}4 \\
2 \\
4 \\
2 \\
3 \\
5\end{array}$ & $\begin{array}{r}10 \cdot 75 \\
11 \cdot 33 \\
11 \cdot 85 \\
9 \cdot 15 \\
11 \cdot 40 \\
11 \cdot 74\end{array}$ \\
\hline Total & 65 & $9 \cdot 13$ & 65 & $10 \cdot 78$ & 63 & $\cdot 11 \cdot 20$ & 44 & $11: 30$ & 36 & $11 \cdot 06$ & 20 & $11 \cdot 21$ \\
\hline Standard deviation & & $2 \cdot 09$ & & $2 \cdot 02$ & & $2 \cdot 21$ & & $2 \cdot 73$ & & $2 \cdot 78$ & & $2 \cdot 03$ \\
\hline Moseuito & & & & & & & & & & & & \\
\hline $\begin{array}{l}\text { Pilot } \\
\text { Navigator }\end{array}$ & $\begin{array}{l}18 \\
18\end{array}$ & $\begin{array}{r}10 \cdot 05 \\
9 \cdot 11\end{array}$ & $\begin{array}{l}10 \\
10\end{array}$ & $\begin{array}{l}10 \cdot 44 \\
10 \cdot 99\end{array}$ & $\begin{array}{l}13 \\
13\end{array}$ & $\begin{array}{l}10 \cdot 98 \\
10 \cdot 80\end{array}$ & $\begin{array}{l}14 \\
13\end{array}$ & $\begin{array}{l}11 \cdot 58 \\
10 \cdot 50\end{array}$ & $\begin{array}{l}12 \\
12\end{array}$ & $\begin{array}{l}11 \cdot 76 \\
11 \cdot 49\end{array}$ & $\begin{array}{l}10 \\
10\end{array}$ & $\begin{array}{l}12 \cdot 02 \\
12 \cdot 97\end{array}$ \\
\hline Total & 36 & $9 \cdot 58$ & 20 & $10 \cdot 72$ & 26 & $10 \cdot 89$ & 27 & $11 \cdot 06$ & 24 & $11 \cdot 63$ & 20 & $12 \cdot 49$ \\
\hline Standard deviation & & $2 \cdot 50$ & & $1 \cdot 79$ & & $1 \cdot 77$ & & $2 \cdot 12$ & & $2 \cdot 08$ & & $2 \cdot 64$ \\
\hline
\end{tabular}


adaptation also appears in the results for the Mosquito squadron, there is a suggestion of a terminal rise which might indicate a physical deterioration resulting from excessive stress associated with the squadron's rather different role. For several reasons such questions can hardly be answered by the datain their present form. The application of tests of significance for the trends observed is complicated by the fact that, owing to attrition and replacement, the population examined differs from stage to stage. Some of the men will

\section{TABLE II}

IntTIAL ACCOMmodation Score AND Survival IN OPERATIONS

\begin{tabular}{|c|c|c|c|c|}
\hline Gauge Score & Total & Survived & $\begin{array}{c}\text { Not } \\
\text { Survived }\end{array}$ & $\begin{array}{c}\text { Survived } \\
(\%)\end{array}$ \\
\hline $\begin{array}{l}\text { Lancaster } \\
\text { Squadron } \\
\text { Good }(7-8 \cdot 5) \\
\text { Poor }(9-)\end{array}$ & $\begin{array}{l}15 \\
21\end{array}$ & $\begin{array}{l}10 \\
10\end{array}$ & $\begin{array}{r}5 \\
11\end{array}$ & $\begin{array}{l}67 \\
48\end{array}$ \\
\hline \multicolumn{5}{|c|}{$\chi^{2}=0.6300, \quad n=1, \quad 0.50>P>0.30$} \\
\hline $\begin{array}{l}\text { Mosquito } \\
\text { Squadron } \\
\text { Good (7-8 -5) } \\
\text { Poor }(9-)\end{array}$ & $\begin{array}{l}29 \\
36\end{array}$ & $\begin{array}{r}12 \\
8\end{array}$ & $\begin{array}{l}17 \\
28\end{array}$ & $\begin{array}{l}41 \\
22\end{array}$ \\
\hline
\end{tabular}

$\chi^{2}=1 \cdot 9409, \quad n=1, \quad 0 \cdot 20>P>0 \cdot 10$

be represented at each stage, others only at some stages, so that not only are the mean scores at different stages not independent of each other, but also some of the differences observed may be the result of differences between individuals rather than the true result of changing adaptation to stress. Further, it is possible that men with subnormal powers of accommodation may be inefficient, e.g. in piloting and gunnery, and therefore less likely to survive a tour. Such a. relationship would tend to lower the average level of accommodation by the selective elimination in action of those with adverse (i.e. high) scores in the Binocular Gauge Test. The possibility of a masking of the results must be considered and the evidence for such a supposition is set out in Table II. In this table are given the members surviving beyond their twentieth sortie among groups achieving good or poor scores in a test applied before the beginning of their tour of operational duty. Although the differences are suggestive, the combination of the uncorrected $\chi^{2}$ values for the two tables gives a value of $\chi^{2}=4 \cdot 053$, with $0 \cdot 20>P>0 \cdot 10$ for $n=2$, so that it is unlikely that selective elimination is a serious source of $\frac{3}{0}$
error in the analysis.

It is easy to show that, as in Table III, there is a $\vec{F}$ significant increase in Gauge Test score, i.e. a lessen- $?$ ing in efficiency of accommodation, after the first ? operational sortie over the resting level measured $\frac{\bar{N}}{\bar{N}}$ before the tour starts. This means that, even in the short term context before the cumulative stress $\triangle$

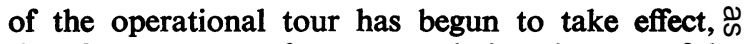
the Gauge Test of aecommodation is a useful $\vec{\circ}$ indicator of reaction to the operational.task.

\section{TABLE III}

Gauge Test Scores before and after First OPERATIONAL SORTIE

\begin{tabular}{|c|c|c|c|c|}
\hline \multicolumn{2}{|c|}{ Lancaster Squadron* } & \multirow[t]{2}{*}{ No. } & \multicolumn{2}{|c|}{$\begin{array}{l}\text { Mean Score } \\
\text { (R. \& L. eyes) }\end{array}$} \\
\hline Crew Dut & & & Before & After \\
\hline $\begin{array}{l}\text { Pilot } . . \\
\text { Navigator ... } \\
\text { Air bomber } \\
\text { Wireless operator } \\
\text { Flight engineer } \\
\text { Air gunner }\end{array}$ & $\begin{array}{l}\ldots \\
\cdots \\
\cdots \\
\cdots \\
\cdots \\
\cdots\end{array}$ & $\begin{array}{r}10 \\
12 \\
11 \\
8 \\
5 \\
19\end{array}$ & $\begin{array}{l}8 \cdot 85 \\
9 \cdot 33 \\
9 \cdot 05 \\
9 \cdot 28 \\
9 \cdot 20 \\
9 \cdot 21\end{array}$ & $\begin{array}{r}9 \cdot 85 \\
11 \cdot 29 \\
10 \cdot 64 \\
10 \cdot 47 \\
10 \cdot 60 \\
10 \cdot 50\end{array}$ \\
\hline Total & . & 65 & $9 \cdot 16$ & $10 \cdot 58$ \\
\hline
\end{tabular}

\begin{tabular}{|c|c|c|c|c|}
\hline \multicolumn{2}{|c|}{ Mosquito Squadron $\dagger$} & \multirow[t]{2}{*}{ No. } & \multicolumn{2}{|c|}{$\begin{array}{l}\text { Mean Score } \\
\text { (R. \& L. eyes) }\end{array}$} \\
\hline \multicolumn{2}{|c|}{ Crew Duty } & & Before & After \\
\hline $\begin{array}{l}\text { Pilot } \\
\text { Navigator }\end{array}$ & $\begin{array}{l}. \\
\ldots\end{array}$ & $\begin{array}{l}18 \\
18\end{array}$ & $\begin{array}{r}11 \cdot 06 \\
9 \cdot 11\end{array}$ & $\begin{array}{l}10 \cdot 75 \\
10 \cdot 86\end{array}$ \\
\hline Total & .. & 36 & $9 \cdot 58$ & $10 \cdot 80$ \\
\hline
\end{tabular}

+ Difference $=1.22, t=3.41$ for $n=35, P<0.01$

For the reasons given above, however, it is less easy to measure the significance of the long-term 0 trends apparent in Table I. The difficulties of non- $-\mathrm{C}$ independence can be overcome by taking from the accumulated records the results at or near $0,5,15,0$ 20 and 25 sorties in individuals who survived the tour and were examined regularly throughout it.? The use of recordings made on the same individuals at regular intervals during the tour simplifies the application of analysis of variance technique to the study of the stage-to-stage trends. The data are $\mathbb{Q}$ set out in full in the appendix (page 109), buto 
TABLE IV

Mran Accommodation at Successive Stages in Tour

\begin{tabular}{|c|c|c|c|c|c|c|c|c|c|}
\hline \multirow{2}{*}{\multicolumn{2}{|c|}{ Squadrơn }} & & \multirow[b]{2}{*}{ No. } & \multicolumn{5}{|c|}{ Stage in Tour } & \multirow{2}{*}{$\frac{}{25}$} \\
\hline & & & & 0 & 5 & 10 & 15 & 20 & \\
\hline $\begin{array}{l}\text { Lancaster } \\
\text { Mosquito }\end{array}$ & $\begin{array}{l}\cdots \\
\ldots\end{array}$ & $\begin{array}{l}\cdots \\
\cdots\end{array}$ & $\begin{array}{r}19 \\
6\end{array}$ & $\begin{array}{l}8 \cdot 74 \\
8 \cdot 00\end{array}$ & $\begin{array}{r}9 \cdot 92 \\
11 \cdot 25\end{array}$ & $\begin{array}{l}11 \cdot 37 \\
10 \cdot 17\end{array}$ & $\begin{array}{l}10 \cdot 82 \\
11 \cdot 42\end{array}$ & $\begin{array}{l}10 \cdot 95 \\
11.42\end{array}$ & $\begin{array}{l}11 \cdot 66 \\
12 \cdot 00\end{array}$ \\
\hline Total & .. & $\ldots$ & 25 & $8 \cdot 56$ & $10 \cdot 24$ & $11 \cdot 08$ & $10 \cdot 96$ & $11 \cdot 06$ & $11 \cdot 74$ \\
\hline Standard & ation & .. & & $1 \cdot 872$ & $2 \cdot 001$ & $2 \cdot 853$ & $2 \cdot 861$ & $2 \cdot 438$ & $2 \cdot 611$ \\
\hline
\end{tabular}

Table IV gives the means at each stage in each squadron together with the standard deviation of the total observations at each stage.

Comparing these results with those in Table $I$, it is clear that the same general trends arise; yet in this instance a terminal change appears in the last stage of the tour in both squadrons. The numbers are rather small, so that it is probably safer to use the whole of the data provided by the repeated measurements on all 25 individuals.

Looking first at the variability of the observations at successive stages, there is a hint that the variability increases with progress through the tour to reach a maximum about the fifteenth sortie. Application of Bartlett's test for the differences between variances, however, shows that they could well have arisen by chance $(0 \cdot 20>P>0 \cdot 10)$. On this basis, homogeneity of variance over the series of arrays can be fairly safely assumed and analysis of variance carried out. The results of that analysis appear in Table $\mathrm{V}$.

From the analysis of Table $\mathrm{V}$ it is clear that, since the " between-stage" mean square is significantly greater than the "error" mean square given by the within-stage residual variance, real differences in mean accommodation score exist at different stages of the operational tour. These differences follow a trend which, as the splitting up of the " between-stage" sum of squares shows, could be best described by fitting a curved regression line of a cubic type. Such a curve was in fact fitted to the data by Fisher's method of using orthogonal polynomials and the closeness of the fit to the means is seen in Fig. 1. This method of fitting a curve to describe each significant feature of the data permits fairly confident interpretation. Clearly, there is a real, in the sense of technically significant, rise in the mean accommodation score in the Binocular Gauge Test during the period of adaptation to operational stress. Between the tenth and the fifteenth sortie, stabilization takes place, but, in the last part of the tour, there is clear evidence of a deterioration in the power of accommodation. In this last respect the present result differs from the

\section{TABLE V}

Analysis of Variance of Mran Gauge Score

\begin{tabular}{|c|c|c|c|c|c|c|c|}
\hline Source & & & & Sum of Squares & D.F. & Mean Square & F. \\
\hline $\begin{array}{ll}\text { Linear term } & \ldots \\
\text { Quadratic } & \ldots \\
\text { Cubic } & \ldots \\
\text { Between stage residual }\end{array}$ & $\begin{array}{l}\cdots \\
\cdots \\
\cdots \\
\cdots\end{array}$ & $\begin{array}{l}\cdots \\
\cdots \\
\cdots \\
\cdots\end{array}$ & $\begin{array}{l}\cdots \\
\cdots \\
\cdots \\
\cdots\end{array}$ & $\begin{array}{r}118 \cdot 8206 \\
18 \cdot 8576 \\
15 \cdot 7236 \\
0 \cdot 6515\end{array}$ & $\begin{array}{l}1 \\
1 \\
1 \\
2\end{array}$ & $\begin{array}{r}118 \cdot 8206 \\
18 \cdot 8576 \\
15 \cdot 7236 \\
0 \cdot 3253\end{array}$ & $\begin{array}{r}49 \cdot 55^{*} \\
7 \cdot 86^{*} \\
6 \cdot 56 \dagger \\
<1\end{array}$ \\
\hline $\begin{array}{l}\text { Between stages } \\
\text { Between individuals } \\
\text { Within stage residual }\end{array}$ & $\begin{array}{l}\cdots \\
\cdots \\
\cdots\end{array}$ & $\begin{array}{l}\cdots \\
\cdots \\
\cdots\end{array}$ & $\begin{array}{l}\cdots \\
\cdots \\
\cdots\end{array}$ & $\begin{array}{l}154 \cdot 0533 \\
590 \cdot 9600 \\
287 \cdot 7800\end{array}$ & $\begin{array}{r}5 \\
24 \\
120\end{array}$ & $\begin{array}{r}30 \cdot 8107 \\
24 \cdot 6233 \\
2 \cdot 3982\end{array}$ & $\begin{array}{l}12 \cdot 85^{*} \\
10 \cdot 27^{*}\end{array}$ \\
\hline Total & . & . & . & $1,032 \cdot 7933$ & 149 & & \\
\hline
\end{tabular}

\footnotetext{
* Highly significant $\mathbf{P}<0.01+$ Significant $\mathbf{P}<0.05$
} 
findings for the other indices of the effects of strain, such as weight loss, used in previous studies on the health of Bomber Command as a whole. In part this may be the result of excessive stress on the Pathfinder Force from which the two squadrons were drawn; but it may equally be an indication of the sensitivity of the method now being discussed.

There is one last point of importance in this context. The 25 individuals whose records have been thus analysed all survived an operational tour. Their response to strain therefore represents the reaction of a sample of the whole crew population of particular quality. Taking their experience as a model of " normality" in response to the stress of bomber -operations, it should be possible to lay down "control" limits" outlining the likely range of individual deviations from a standard expectation based on this response curve.

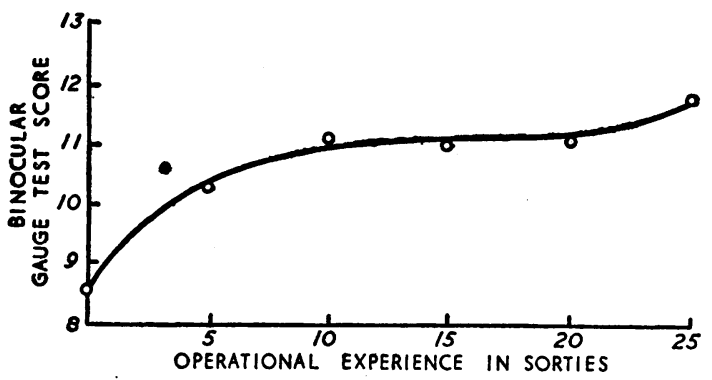

Fig. 1. Trend in accommodation test results during operational tour.

The variation between individuals is, of course, considerable. At any particular stage in the tour the accommodation scores for a series of individuals will vary about the point on the curve appropriate to that stage in the tour with a variance which can be estimated from Table V. The difference between the "between-individual" mean square and the " within-stage" mean square $(22 \cdot 2251)$ is due to the variance between individual levels which can be estimated by dividing $22 \cdot 2251$ by 6 , the number of stages upon which it is based. To this result (3.7041) must be added the final residual variance which is a measure of the variability in the scores of any one individual round his own mean score at any one point in the curve tour $(2 \cdot 3982)$. The resulting variance estimate $(6 \cdot 1023)$ gives a standard deviation of $\sqrt{6 \cdot 1023}=2 \cdot 47$ for the variation of the scores for a series of individuals round the mean appropriate to some fixed stage in the tour. Assuming normality of distribution and taking the limit to the nearest point of the measuring scale $(2 \cdot 5)$ it might be said that only one in twenty individuals $\frac{3}{\mathrm{D}}$ of a group measured at the same stage in their? tour will have a score differing by more than $\vec{F}$ $2 \times 2 \cdot 5=5$ units from the group mean at that stage $\frac{\vec{\sigma}}{\sigma}$

These limits can be minimized and thus made든 more useful by eliminating this variability between $\bar{\omega}$ individuals. This can be done by relating an $\overrightarrow{\mathbb{\Phi}}$ individual's score at each stage to the resting score $\varrho$ of that individual before starting the operationales tour, i.e. the score at any stage is expressed as a $\overrightarrow{0}$ deviation from the base line of the resting score. $\overrightarrow{.}$ The expected " normal" upward trend from this base line is given by the curve fitted to the means $\frac{}{\infty}$. starting from the resting score. Round this $\stackrel{5}{)}$ expectation there will be, at all stages, a variation $\omega$

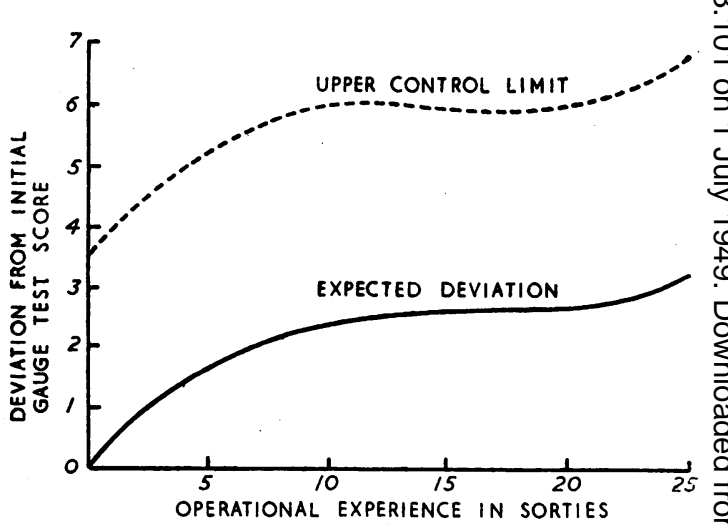

Fig. 2. Control limit of accommodation scores during operational tour.

in score for the same individual of a size indicated $\stackrel{?}{?}$ by the "within-stage" variability of Table $\mathrm{V}$ $(2 \cdot 398)$. This variance will apply to both initial. and subsequent measurements so that the signifi- $O$ cance of the difference between them must be assessed in terms of the standard error of that $\frac{}{3}$ difference which is derived from the sum of their $\frac{}{2}$ variances: $\sqrt{2 \times 2 \cdot 398}=2 \cdot 19$.

This value of $2 \cdot 19$ units is a guide to the $\tilde{O}^{\circ}$ variability likely to be found round the expected $N$ difference between the initial observed resting score $N$ and measurements made at subsequent stages of the $\omega$ tour. Certainly such an estimate of variability is at best an estimate which is least accurate at the extremes of the operational experience scale, but $\Phi$ within this range of experience it does give an adequate indication of the limits of "normal "प variability in the differences between resting and $\frac{\vec{D}}{\mathrm{D}}$ subsequent scores. Control limits, based on this $\frac{\rho}{\Phi}$ estimate of variability, can thus be laid down so as $\varrho$ to include all but any desired proportion of the? 
scores. An upper limit set at 3.6 units above the expected difference for each stage in the tour, for example, as in Fig. 2, where $3 \cdot 6=$ normal deviate for 95 per cent. $(1 \cdot 65) \times$ standard deviation $(2 \cdot 19)$, will include all but 5 per cent. of the scores likely to be observed in a " normal " group of individuals. Only if an individual's score at any point in his tour is above the "upper control limit" appropriate to that stage could it be suggested that his reaction to stress was definitely unusual or significant. Whether such an unusual physical reaction is necessarily predictive or indicative of illness cannot, of course, be determined from the present data, but such a deviation from expectation certainly suggests that his resilience under strain is suspect and that particular care must be taken in his medical supervision.

Ocular Balance.-The results of the tests of ocular balance used (the Maddox Wing and the Bishop Harman Diaphragm tests) were obtained for the same 25 individuals for whom records were available throughout the tour. The unusual metric used in these tests makes any sophisticated analysis quite unrealistic. It is difficult, for example, to give numerical meaning to a shift from exophoria of two degrees to an esophoria of one degree, and it is probably adequate merely to note the changes in distribution with increasing experience in a group of flying men. This is done in Tables VI and VII where, for the same 25 men, are given the distributions of the results of Maddox Wing and Bishop Harman Diaphragm tests applied at different stages of the tour. In the first case, the $\chi^{2}$ test would suggest that the changes in distribution differ insignificantly from stage to stage. This test, however, takes no account of trend and there is some indication that there is a decrease in the proportion of esophoric readings after the tenth sorties. This change is so slight, however, that it seems unlikely to have much practical value in this context. Similarly, however, the scores of the second test were divided up, the resulting distributions were remarkable only in their stability, and statistical

TABLE VI

Distribution of Maddox Wing Test Scores THROUGHOUT TOUR

\begin{tabular}{|c|c|c|c|c|c|c|}
\hline & \multicolumn{6}{|c|}{ Stage in Tour } \\
\hline & 0 & 1 & 5 & 10 & 15 & 25 \\
\hline $\begin{array}{l}\text { Considerable esophoria } \\
\begin{array}{l}(6+) \\
\text { Remainder }\end{array}\end{array}$ & $\begin{array}{ll}. \quad 15 \\
\cdots \quad 10\end{array}$ & $\begin{array}{l}15 \\
10\end{array}$ & $\begin{array}{l}14 \\
11\end{array}$ & $\begin{array}{l}10 \\
15\end{array}$ & $\begin{array}{l}11 \\
14\end{array}$ & $\begin{array}{l}11 \\
14\end{array}$ \\
\hline
\end{tabular}

TABLE VII

Distribution of Bishop Harman Diaphragm TEST SCORES THROUGHOUT TOUR

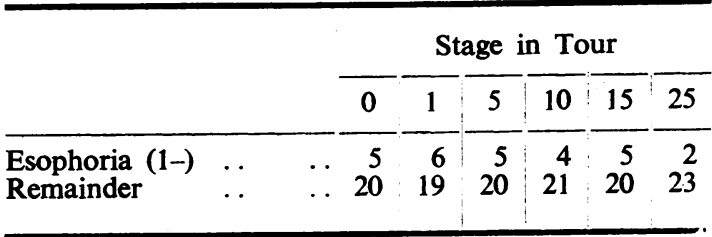

tests are superfluous. It would appear, then, that neither of these two tests gives the same promise as a measure of the response to stress as does the gauge test of accommodation.

Physiological Diplopia.-The average values found by using the test of physiological diplopia at each stage in the tour are given in Table VIII. where the observations are expressed in terms of the deviation from the resting value. It is clear that, although there are differences in a negative direction between the resting value and the score made on test on

\section{TABLE VIII}

Mean Deviation from Resting Result in Diplopia Test throughout Tour

\begin{tabular}{|c|c|c|c|c|c|c|c|c|c|c|c|c|}
\hline \multirow{3}{*}{ Squadron } & \multicolumn{10}{|c|}{ Stage in Tour } & & \\
\hline & \multicolumn{2}{|r|}{$1-5$} & \multicolumn{2}{|c|}{$6-10$} & \multicolumn{2}{|c|}{$11-15$} & \multicolumn{2}{|r|}{$16-20$} & \multicolumn{2}{|c|}{$21-25$} & \multicolumn{2}{|r|}{$26-30$} \\
\hline & No. & Mean & No. & Mean & No. & Mean & No. & Mean & No. & Mean & No. & Mean \\
\hline $\begin{array}{l}\text { Lancaster } \\
\text { Mosquito }\end{array}$ & $\begin{array}{l}56 \\
20\end{array}$ & $\begin{array}{r}+0 \cdot 1607 \\
-0 \cdot 2500\end{array}$ & $\begin{array}{l}64 \\
26\end{array}$ & $\begin{array}{l}-0.8438 \\
-0.5385\end{array}$ & $\begin{array}{l}44 \\
26\end{array}$ & $\begin{array}{l}-0.5455 \\
-0.2692\end{array}$ & $\begin{array}{l}36 \\
24\end{array}$ & $\begin{array}{l}-2 \cdot 7222^{*} \\
-0 \cdot 7083\end{array}$ & $\begin{array}{l}20 \\
20\end{array}$ & $\begin{array}{l}-0.9500 \\
-1.0000\end{array}$ & $\begin{array}{l}15 \\
12\end{array}$ & $\begin{array}{l}-3 \cdot 4000^{*} \\
+1 \cdot 0000\end{array}$ \\
\hline
\end{tabular}


return from a sortie, these differences reach significant levels on only two occasions. Further, there is no consistent trend between the mean values at different stages of the tour at all comparable with the trend seen in accommodation and the other physical indicators of the effect of stress. For these reassons, it seems fairly certain that this test, at least in its present form, is not of value in the detection of either short-term or cumulative fatigue.

\section{Discussion}

A review of these results suggests that in tests of accommodation we have a sensitive, accurate indicator of the reaction of individuals to a harassing environment. The use of a sensitive test in repeated examination of the same individual during a period of strain gives the same indications as do cruder measures, such as loss in bodyweight, when assessed in different individuals at different stages in their tour. It is also clear that the tests of ocular poise and of physiological diplopia give no such promise.

In the supervision of the health of flying men, the indications of terminal deterioration appearing in this study may be useful in determining the optimum limits of the operational tour. As has been shown, however, individual differences are considerable but, if each individual's performance on test can be related to his own resting level before the period of stress began, the general experience of the group to which he belongs can be used as a guide to the reaction likely to be observed. The deviation of an individual's score from that expectation must be assessed in terms of the usual variability likely to be found between repeated observations, and this variability can be readily estimated.

The possibility of using similar techniques in the study of short and long-term fatigue in industry should be considered. Admittedly the physical changes noted in this survey have been the result of a stress of particular intensity. But they have arisen in men of exceptional calibre. The less dramatic strains in industry operate on a much less highly selected population, and with large numbers and more sensitive tests useful indications of group reaction to environment may be obtained.

\section{SUMmaRY AND CONCLUSIONS}

A statistical analysis has been made of the results of a survey of the effects of operational flying stress on the visual function of men of two bomber squadrons of the R.A.F. during the later stages of World War II. It is suggested that tests of accom- modation were sensitive indicators of the reactions $\frac{2}{2}$ of men to the exceptional stress of their environment ? at that time.

Such tests, repeated on the same individuals at intervals throughout the tour, gave substantially the same indications as did the trend of weight $\frac{\overline{0}}{\overline{0}}$ differences between a large series of different men $\vec{\Phi}$ measured at different stages in the tour. In both $\bigcirc$ instances there was evidence of a period of adapta- $ळ$ tion to stress when mean weight fell and the power $\overrightarrow{0}$ of accommodation deteriorated, but then, after $\overrightarrow{.}$ about the tenth sortie in a tour limited to 30 sorties, $\vec{\omega}$ stabilization at a new level took place. Confirma- $\frac{\widehat{D}}{\mathrm{D}}$ tion of this interpretation comes from similar trends $\stackrel{\odot}{\rho}$ in the incidence of psychological disorder at different $\omega$ stages in the tour.

The use of a test of accommodative power had $\vec{\circ}$ additional advantages: it seems to be able to $\vec{\circ}$ discriminate in a fairly objective fashion between resting performance and performance in the fatigue $\vec{c}$ state on completion of a sortie. More important, however, is the suggestion that by the repeated use of sensitive tests on the same individuals, it might be possible to detect long-term trends in cumulative fatigue. The value of such indications in laying down optimum limits of duration of operational employment is discussed and suggestions are made for the use of the estimates of variation in an individual's performance from time to time to $\varrho$ estimate the significance of his deviation from the $\overrightarrow{\vec{O}}$ average performance of a group subject to the same cumulative strain.

The more precise methods of supervision of health suggested in this study may have a wider application in occupational medicine.

Similar study of tests of ocular poise and physio- $\frac{0}{-}$ logical diplopia gave no clear promise of usefulness in this field.

I am indebted to Sir Charles Symonds and Professor 윽 A. Bradford Hill, Consultants to the Royal Air Force in $D$ Neuropsychiatry and Medical Statistics, for their advice, and to the Director-General of Medical Services of the Royal Air Force, Air Vice Marshal P. C. Livingston, both $\mathrm{N}$ for his help while Consultant in Ophthalmology and for permission to publish this report. To Mrs. K. M. Bull, $O$ Miss B. M. Miller, and Miss O. M. Penfold I am obliged $N$ for their clerical and computing assistance, and to Mrs.
M. G. Young for drawing the diagrams.

References
"Medical Examination for Fitness for Flying" (1941).
Air Ministry Air Publication No. 130.
Reid, D. D. (1947). Air Ministry Air Publication
No. 3139. Chap. XIX.
Symonds, C. P., and Williams, D. J. (1947). Air
Ministry Air Publication No. 3139. Chap. IV.


APPENDIX

Binocular Gauge Test Score at different Stages in Tour

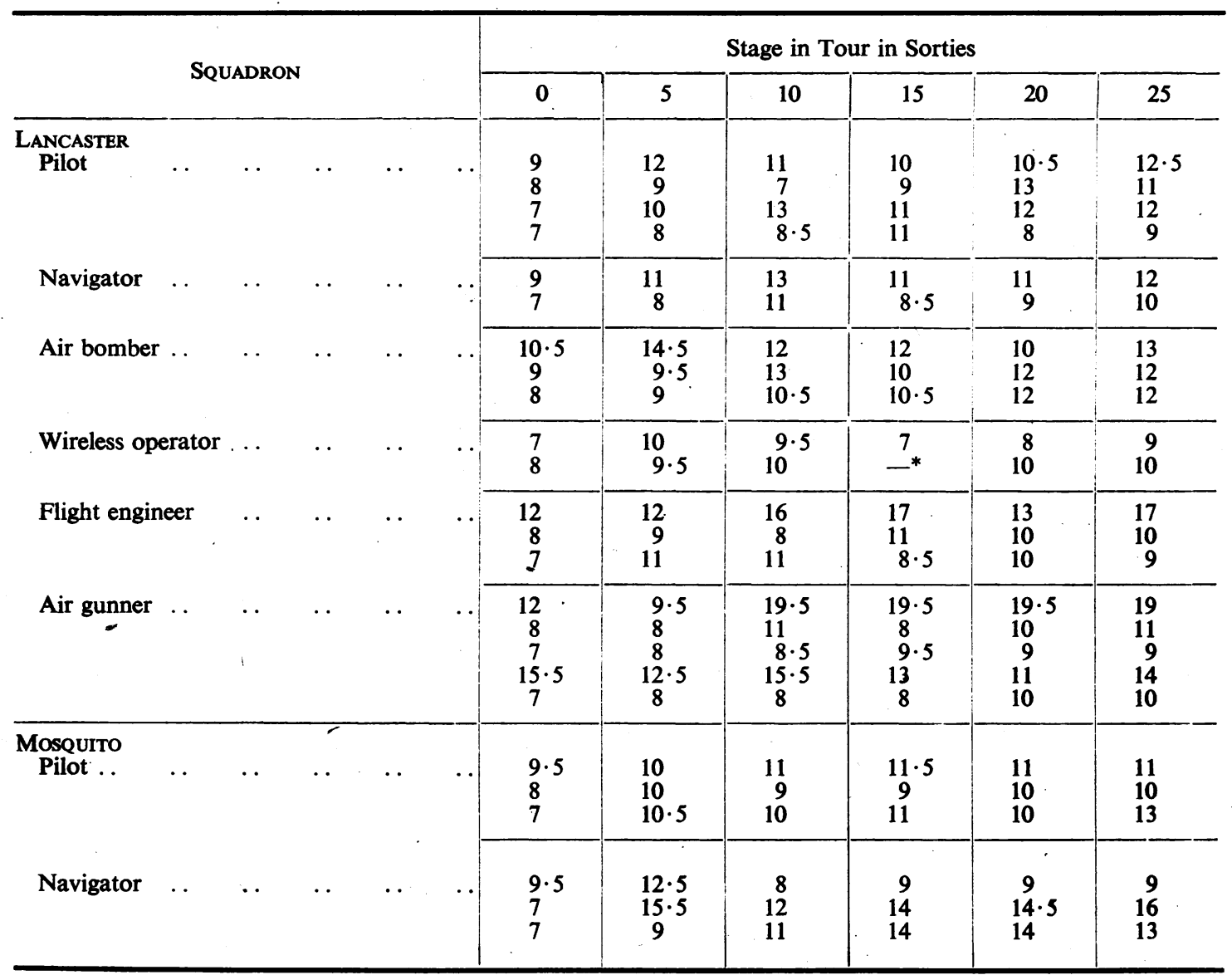

"Value estimated by " missing plot" technique was used in analysis. 